\title{
Microstructure evolution and densification during spark plasma sintering of
} nanocrystalline W-5wt.\% Ta alloy

\author{
Ajeet K. Srivastav ${ }^{1 *}$, Suresh Bandi ${ }^{1}$, Abhishek Kumar ${ }^{2}$ and B.S. Murty ${ }^{3,4}$ \\ ${ }^{1}$ Department of Metallurgical and Materials Engineering, Visvesvaraya National Institute of \\ Technology, Nagpur - 440010, India \\ ${ }^{2}$ Institute for Frontier Materials, Deakin University, Geelong, Geelong, VIC 3216, Australia \\ ${ }^{3}$ Indian Institute of Technology Hyderabad, Kandi, Sangareddy - 502285, India \\ ${ }^{4}$ Department of Metallurgical and Materials Engineering, Indian Institute of Technology \\ Madras, Chennai - 600036, India
}

\begin{abstract}
The present work reports the effect of $\mathrm{Ta}$ on densification and microstructure evolution during non-isothermal and spark plasma sintering of nanocrystalline W. Nanocrystalline W5wt.\%Ta alloy powder was synthesised using mechanical alloying. The nanocrystalline powder was characterised thoroughly using X-ray diffraction line profile analysis. Furthermore, the shrinkage behaviour of nanocrystalline powder was investigated during non-isothermal sintering using dilatometry. Subsequently, the alloy powder was consolidated using spark plasma sintering up to $1600^{\circ} \mathrm{C}$. The role of Ta on stabilising the microstructure during spark plasma sintering of nanocrystalline $\mathrm{W}$ was investigated in detail using electron backscatter diffraction. The average grain size of spark plasma sintered W-5wt.\%Ta alloy was observed as $1.73 \pm 1 \mu \mathrm{m}$.
\end{abstract}

Keywords: Nanocrystalline alloys; non-isothermal sintering; Kirkendall porosity; spark plasma sintering

\footnotetext{
* Corresponding Author

Email: srivastav.ajeet.kumar@gmail.com
} 


\section{Introduction}

Tungsten (W) has evolved as a primary candidate for plasma-facing material in nuclear fusion devices owing to its high melting point [1,2], low sputtering coefficient [3], high thermal conductivity [4], and low radioactive fuel retention [5,6]. However, the inherent lowtemperature brittleness limits its use for structural applications [7,8], particularly as this property severely worsens under irradiation conditions $[9,10]$. Also, low fracture toughness, high-temperature oxidation, and recrystallisation embrittlement are other drawbacks to be considered [11]. In addition to $\mathrm{W}$-based composite materials, alloying and imparting nanocrystallinity in the $\mathrm{W}$ have been suggested for improving the ductility and bringing down the ductile to brittle transition temperature (DBTT) in the material [12-14]. Besides, the grain refinement and refinement-induced large grain-boundary volume fractions are encouraging for oxidation and radiation resistance [15,16]. However, alloying could be a possible approach, along with grain refinement, to overcome the drawbacks mentioned above by improving the material's properties.

Alloying W with tantalum (Ta) brings the possible enhancement in the ductility, decreases the water oxidation, helps in mitigating surface cracking caused by the highfluence threshold for nanostructure formation on the surface of $\mathrm{W}$ [5,17]. In addition, Ta lowers the cluster formation under irradiation condition and hence the chances of embrittlement in $\mathrm{W}$ and $\mathrm{W}$ alloys [18]. However, W-based binary alloys are known for Kirkendall porosity which makes them difficult to consolidate conventionally $[19,20]$. Therefore, for such alloy powders it is crucial to choose an appropriate sintering process for improving the grain refinement and the densification of the final structure. Recently, spark plasma sintering (SPS) has been established as a promising consolidation technique for various materials. The process can facilitate a high degree of densification at the lowest temperatures and for shorter periods with better grain refinement [21,22]. Moreover, Srivastav et al. [23] has shown that localised diffusion-couple-induced pore evolution could be advantageous for densifying such materials by adopting the SPS process on account of the inherent localised heating mechanisms.

In the current work, a nanocrystalline W-5wt.\%Ta alloy powder was synthesised by mechanical alloying. First, the microstructure evolution and shrinkage behaviour of the alloy powder was studied during non-isothermal sintering using dilatometry. Subsequently, the 
alloy powder was consolidated via SPS to achieve a nearly $95 \%$ relative density with better grain refinement. The study demonstrates that SPS can be a potential consolidation route to densify such materials compared to conventional methods.

\section{Experimental details}

The W-5wt.\%Ta alloy was prepared via mechanical alloying using a high-energy planetary ball mill (Fritsch Pulversitte-5, Germany) equipped with a set of tungsten carbide (WC) vials and balls (10 mm diameter) for grinding. The milling was employed for $6 \mathrm{~h}$ at $300 \mathrm{rpm}$ using a 10:1 ball-to-powder ratio with toluene as a process-controlling agent.

$\mathrm{X}$-ray diffraction profile of mechanically milled W-5wt.\% Ta alloy powder was collected using an X'Pert Pro (PANalytical, The Netherlands) X-ray diffractometer with $\mathrm{Cu}$ $\mathrm{K} \alpha$ radiation in the $2 \theta$ range $10-140^{\circ}$ using $0.02^{\circ}$ step size with a $30 \mathrm{~s}$ time per step. A lineprofile analysis [23-26] was used for profile fitting using the pseudo-Voigt function in High Score Plus software (version 3.0e). Furthermore, the full width at half-maximum (FWHM) and the shape parameter $(\eta)$ from the fitted profile were used as input parameters for the double-Voigt analysis [27,28] using the BREADTH programme (version 4) [29] for the quantification of crystallite size and root-mean-square strain (RMSS) in the milled powder sample. It is worth noting here that the FWHM and $\eta$ input parameters are transformed to the

Cauchy $\left(\beta_{C}\right)$ and the Gaussian $\left(\beta_{G}\right)$ part of the corresponding Voigt function using the approximations as discussed earlier [30,31].

Dilatometry studies were performed on a cold compact (a cylindrical shaped pellet with $8 \mathrm{~mm}$ diameter) of milled powder using a dilatometer, Setaram, Setsys Evolution. The cold compact was sintered non-isothermally in an argon atmosphere with a constant heating rate of $20 \mathrm{~K} \mathrm{~min}^{-1}$ up to $1600^{\circ} \mathrm{C}$ under $\sim 0.6 \mathrm{~N}$ load. The effect of alloying with Ta on the densification behaviour of nanocrystalline $\mathrm{W}$ was explored with the support of shrinkage data obtained during the experiment.

Consolidation of the W-5wt.\%Ta powder was achieved using SPS (spark plasma sintering, Dr. Sinter SPS-650 machine, Sumitomo Metals, Japan). Densification of the powder was carried out in a cylindrical graphite die with $10 \mathrm{~mm}$ diameter. The process was taken up to $1600^{\circ} \mathrm{C}$ with a heating rate of $100^{\circ} \mathrm{C} \min ^{-1}$ and a dwell period of $5 \mathrm{~min}$. A uniaxial pressure of $50 \mathrm{MPa}$ was applied throughout the process.

Microstructural investigations and elemental analysis were conducted on nonisothermally sintered and SPS samples using a scanning electron microscope (FEI QUANTA 
400 manufactured by FEI, USA) equipped with an energy-dispersive X-ray spectrometer (EDAX-AMETEK Materials Analysis Division, USA). Crystal orientation measurements were made on SPS sample using an HKL Oxford system attached to an FEG-SEM (Zeiss Gemini 300).

\section{Results and discussion}

An XRD pattern of milled W-5wt.\%Ta alloy powder is illustrated in Fig.1(a). The magnified (200) peak as shown in the inset clearly indicates the broadened peak profile and undissolved Ta peak. Besides instrumental effects, the physical origin of the peak broadening is attributed to diffraction-order-independent 'coherently diffracting domain (crystallite) size' and diffraction-order-dependent 'lattice distortion/strain' in reciprocal space [32].
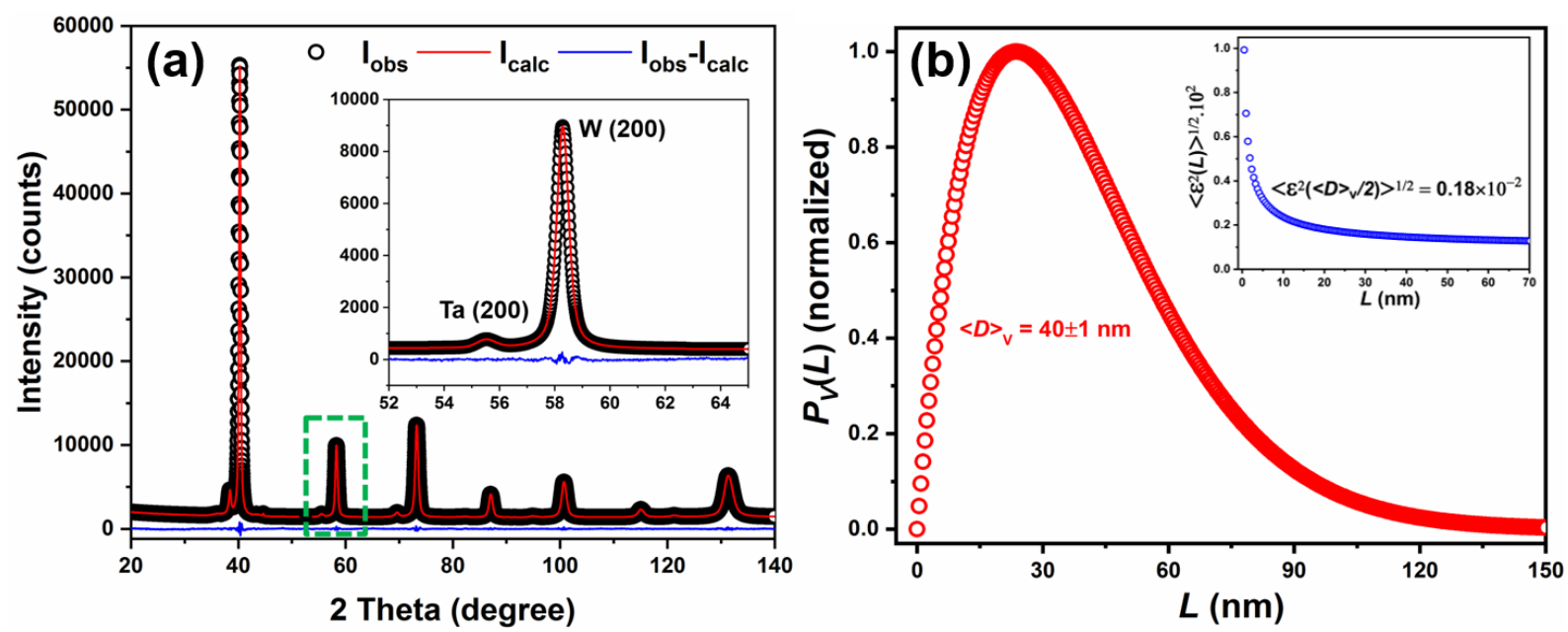

Fig.1. (a) The XRD pattern of milled W-5wt.\% Ta alloy powder with the fitted profile function, and (b) the crystallite size distribution and the root-mean-square strain over the column length.

Practically, it is always a concern how to deconvolute size and strain effects. Nowadays, the double-Voigt approach has been widely accepted for such deconvolution [32]. Here, a Voigt function approximation for both size- and strain-broadened profiles is considered.

The Fourier transform of the Voigt function in terms of distance, $L$, having size and strain components can be represented as an analytical expression [33,34]:

$$
A(L)=\exp \left[-2 L \beta_{C}-\pi L^{2} \beta_{G}^{2}\right]
$$

The size $(S)$ and strain $(D)$ contributions can be deconvoluted with the assumption that the Cauchy and the Gaussian functions represent the size and strain parts, respectively 
$[27,35,36]$. However, both the size and the strain effects can again be approximated by Voigt functions to tackle the non-ideality situation. As the convolution of two Voigt functions is again a Voigt function, the Cauchy $\left(\beta_{S C}\right.$ and $\left.\beta_{D C}\right)$ and Gaussian $\left(\beta_{S G}\right.$ and $\left.\beta_{D G}\right)$ components for both the size and strain can be represented as [27,34,36]:

$\beta_{C}=\beta_{S C}+\beta_{D C}$

$\beta_{G}^{2}=\beta_{S G}^{2}+\beta_{D G}^{2}$

The $\beta_{S C}, \beta_{D C}, \beta_{S G}$, and $\beta_{D G}$ unknowns can be determined using input parameters for two/or more peaks of the profile.

Furthermore, the area $\left(P_{S}(L)\right)$ and the volume-weighted $\left(P_{V}(L)\right)$ column length distribution functions can be obtained by inserting the $\beta_{S C}$ and $\beta_{S G}$ values in equation 1 to obtain the size coefficient $\left(A_{S}(L)\right)$ and using the relation $[27,34,36]$ :

$$
P_{S}(L) \propto \frac{d^{2} A_{S}(L)}{d L^{2}} ; P_{V}(L) \propto L \frac{d^{2} A_{S}(L)}{d L^{2}}
$$

From equation 3 , the surface-weighted $\left(\langle D\rangle_{S}\right)$ and volume-weighted $\left.(<D\rangle_{V}\right)$ column length can be calculated using the expression $[27,34,36]$ :

$$
<D>_{S, V}=\frac{\int_{0}^{\infty} L P_{S, V}(L) d L}{\int_{0}^{\infty} P_{S, V}(L) d L}
$$

Also, the mean-square strain (MSS) as a function of averaging distance $L$ can be obtained by using the expression $[27,34,36]$ :

$$
<\varepsilon^{2}(L)>=\frac{1}{s^{2}}\left[\frac{\beta_{D G}}{2 \pi}+\frac{\beta_{D C}}{\pi^{2}}\left(\frac{1}{L}\right)\right]
$$

The structural parameters of the milled powder were obtained by following the double-Voigt approach as discussed above. Typical for any distribution function, the Cauchy component $\left(\beta_{S C}, 2.33 \times 10^{-3} \AA^{-1}\right)$ of the size-broadening profile dominates over the Gaussian component $\left(\beta_{S G}, 0.612 \times 10^{-3} \AA^{-1}\right)$. However, the Gaussian component $\left(\beta_{D G}, 1.11 \times 10^{-3} \AA^{-1}\right)$ of the strain-broadening profile overshadows the Cauchy component $\left(\beta_{D C}, 0.898 \times 10^{-3} \AA^{-1}\right)$. This indicates that the strain contribution throughout the domains is predominated over by either the fluctuation in the density of embedded atoms or dislocation-cell walls rather than the strain around the individual dislocations [37-39]. It should be pointed out here that the 
integral breadth was contributed to more by size than by the strain part. Therefore, strain does not play a major role in terms of peak broadening in the present case [27].

The crystallite size (column length) distribution for $\mathrm{W}$ is shown in Fig.1(b). The volume-weighted average crystallite size was found to be as $40 \pm 1 \mathrm{~nm}$. The inset shows the root-mean-square strain (RMSS) as a function of $L$. Typical of the double-Voigt analysis, the RMSS falls off with $1 / L$. The RMSS averaged over a distance $\langle D\rangle_{\mathrm{v}} / 2$ was estimated as $0.18 \times 10^{-2} \pm 0.2 \times 10^{-4}$. The lattice parameter for $\mathrm{W}$ in the mechanically milled $\mathrm{W}-5 \mathrm{wt} . \% \mathrm{Ta}$ was calculated using the Nelson-Riley method [40]. The lattice parameter and the NelsonRiley function (NRF) corresponding to each peak reflection were calculated. The precision lattice parameter was obtained from the intercept of a linear fitting of lattice parameter versus NRF plot.

The calculated lattice parameter was $0.31644 \mathrm{~nm}$, which is a decrease of $0.013 \%$ and $0.025 \%$ when compared to mechanically milled $\mathrm{W}$ with the same milling parameters and unmilled W powder, respectively [25]. The reduced crystallite size and interfacial stresses evolved during the milling could reduce the lattice parameter of the milled W. However, the decrement in lattice parameter is doubled for $\mathrm{W}$ in the presence of $\mathrm{Ta}$ in the present case compared to an earlier report for milled W [25]. In fact, Ta possesses a higher atomic radius and a higher lattice parameter than W. In principle, the lattice parameter of W should increase with alloying by Ta. As reported by Romig and Cieslak [41], the interdiffusion distances between $\mathrm{W}$ and $\mathrm{Ta}$ were found to be $<1 \mu \mathrm{m}$ at $1300^{\circ} \mathrm{C}$ after 220 days. This additionally confirms the extremely sluggish diffusion kinetics at the W/Ta interface. The Ta evidenced in the XRD pattern indicates that the Ta has not shown considerable tendency to diffuse at the W/Ta interface. In addition, it has been shown that $\mathrm{W}$ diffuses 100 times faster in pure Ta than does Ta in $\mathrm{W}$ [42]. Consequently, $\mathrm{W}$ has more of a tendency to dissolve in Ta than Ta does in W. Also, the Ta lattice parameter was estimated as $0.31914 \mathrm{~nm}$, which is lower than that of the as-received Ta powder $(0.33011 \mathrm{~nm})$. Hence, Ta becomes a Ta-rich solid solution in the course of milling and further processing [43]. In addition, grain-boundary interfacial stresses accompanied by the evolution of reduced crystallite size and non-equilibrium grain boundaries [26], should result in the lower lattice parameter of W as calculated and discussed above.

Fig.2(a) shows the shrinkage (\%) and shrinkage rate (\%/min) during non-isothermal sintering of the nanocrystalline $\mathrm{W}-5 \mathrm{wt} . \%$ Ta alloy powder. There is first an expansion up to $10.5 \%$ at $1000^{\circ} \mathrm{C}$ followed by a shrinkage up to $5.6 \%$ at the highest temperature of $1600^{\circ} \mathrm{C}$. 
Initially, the maximum expansion rate was observed as $1.25 \% / \mathrm{min}$ at approximately $700^{\circ} \mathrm{C}$. Later, the maximum shrinkage rate was $1.1 \% / \mathrm{min}$ at nearly $1400^{\circ} \mathrm{C}$. The pronounced expansion can be well understood in view of a Kirkendall effect arising from the different atomic mobilities of $\mathrm{W}$ and Ta as reported by Lenz and Riley [19]. The Kirkendall porosity might play a major role in the early expansion of $\mathrm{W}-\mathrm{Ta}$, followed by a sudden drop as shrinkage caused by enhanced interdiffusion at higher temperatures and aided by alloying where the Kirkendall effect plays its role in a positive way [20,23].
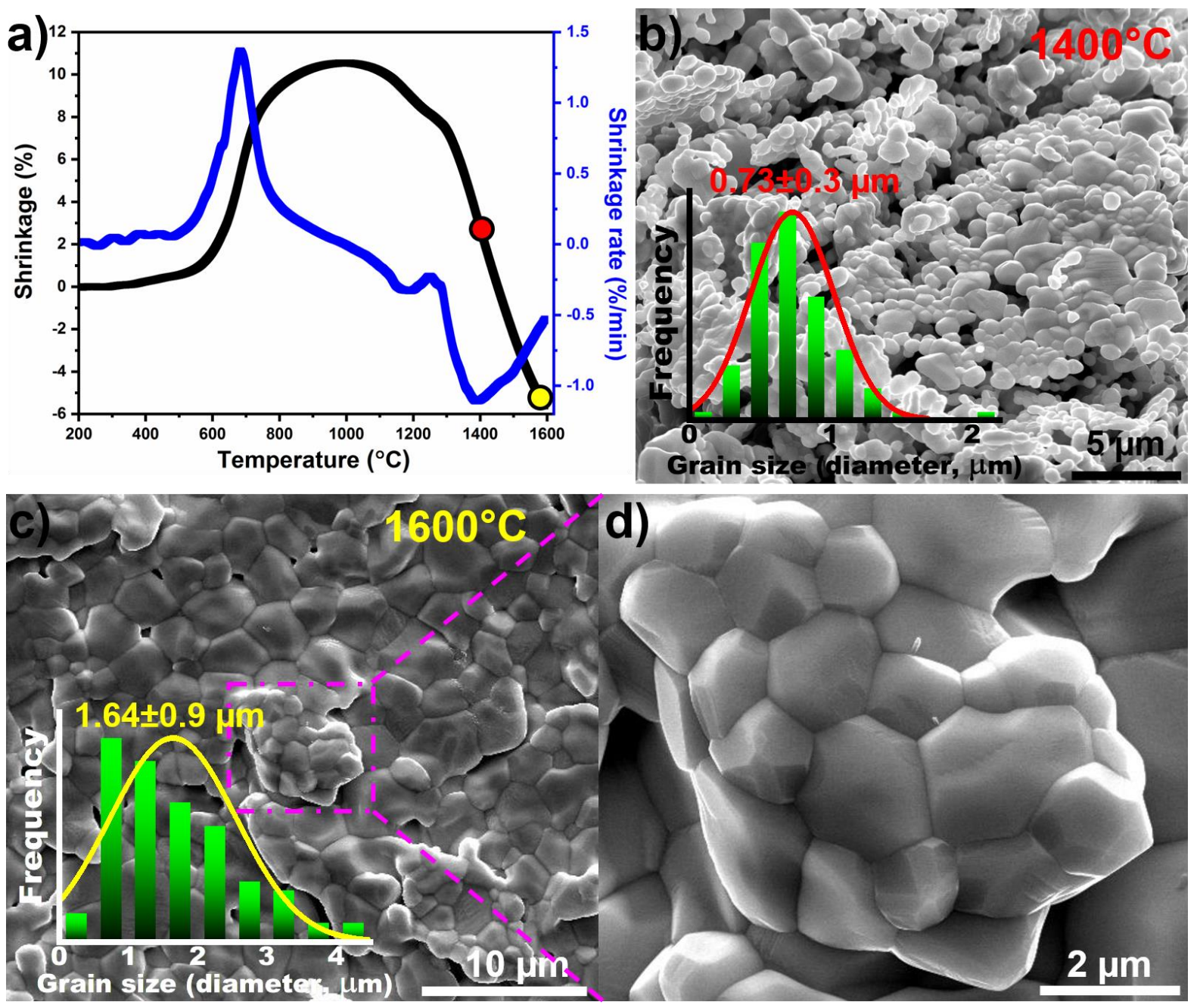

Fig.2. (a) The shrinkage and shrinkage rate of nanocrystalline W-5wt.\% Ta alloy powder during non-isothermal sintering, and the morphology and the grain-size distribution for the sample non-isothermally sintered up to (b) $1400^{\circ} \mathrm{C}$, and (c) $1600^{\circ} \mathrm{C}$. Magnified view of the locally evolved faceted and grainy structure from the square section in (c) is illustrated in (d).

To understand this further, the experiment was performed at an intermediate temperature up to $1400^{\circ} \mathrm{C}$ as well. The morphological evolution as illustrated in Fig.2(b) shows a Kirkendall-effect-induced porous structure with locally interconnected grains. The 
grain-size distribution is shown as an inset. The average grain size was estimated as $0.73 \pm 0.3 \mu \mathrm{m}$. The localized densification improves as sintering proceeds further up to $1600{ }^{\circ} \mathrm{C}$ as illustrated in Fig.2(c). However, whole sintering does not change anything at the larger scale beyond those occurring in the initial stages of sintering in terms of shrinkage behavior (maximum 5.6\%). The grain-size distribution and the average grain size were estimated in the light of the localized densification as illustrated in the inset to Fig.2(c). As expected, the localized densification enhances with grain growth. The average grain size was found to be $1.64 \pm 0.9 \mu \mathrm{m}$. A magnified view of the evolved grainy structure with welldeveloped grain boundaries and facets is shown in Fig.2(d).
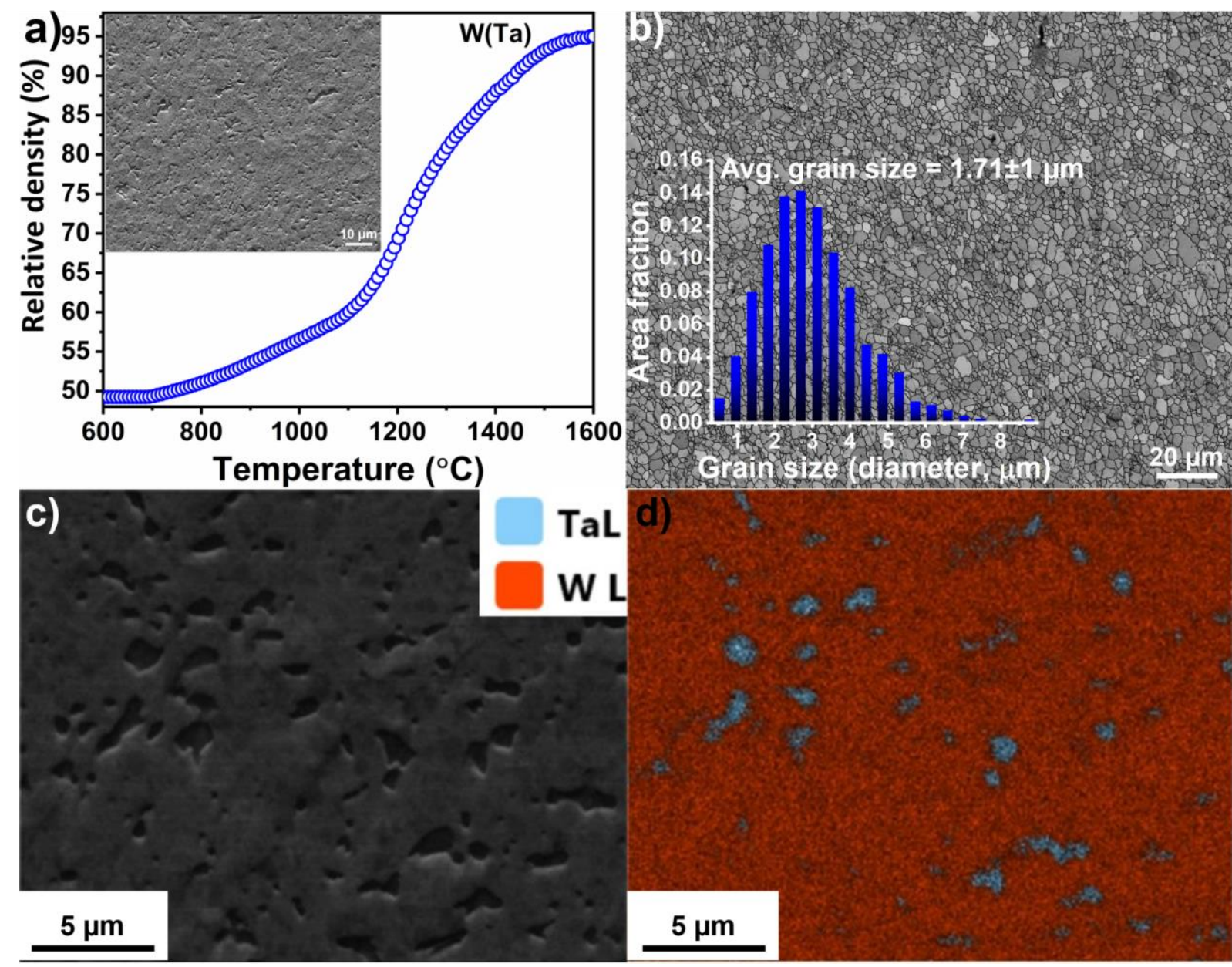

\section{$5 \mu \mathrm{m}$}

Fig.3. (a) The densification curve during SPS of nanocrystalline W-5wt.\%Ta alloy powder with secondary electron micrograph (inset), and (b) image quality (IQ) map showing the grain and grain boundaries with grain-size distribution (inset), (c) back-scatter electron miocrograph, and (d) elemental mapping showing the two-phase structure with Ta-rich solid solution and $\mathrm{W}$ as matrix. 
Unlike non-isothermal sintering, the densification initially occurs at a slower rate followed by a steep rise in density until finally saturating at nearly $95 \%$ relative density. The SEM micrograph, shown as an inset, confirms the dense microstructure after the SPS. The microstructure of the consolidated sample was investigated using EBSD. An image quality (IQ) map was constructed from the EBSD data for the SPS consolidated sample. The obtained IQ map, shown in Fig.3(b), clearly shows the grains and grain boundaries that evolved during the sintering process. The grains are mostly uniform in size, with an average size estimated as $1.73 \pm 1 \mu \mathrm{m}$. Interestingly, the average grain size of the SPS consolidated sample is close to the grain size as observed during non-isothermal sintering up to $1600^{\circ} \mathrm{C}$. Almost similar grain sizes, irrespective of the densification process, suggests the same origin of microstructural stability during the sintering process. It is worth noting here that the pure $\mathrm{W}$ processed under similar conditions results in grain sizes almost 6.5 times bigger than in the present case [23].

To understand the role of $\mathrm{Ta}$ on grain-growth retardation during SPS of nanocrystalline $\mathrm{W}$, elemental mapping was performed on the sample. The elemental analysis of the microstructure shows a two-phase structure with a Ta-rich phase along with the $\mathrm{W}$ as the matrix phase. The darker contrast in the back-scatter SEM image is mapped as Ta in light-blue colour in the elemental mapping, whereas $\mathrm{W}$, showing a greyish colour in the backscatter SEM image, is mapped in orange colour. As discussed above, the Ta becomes a Tarich solid solution [43] appearing as dark contrast in the BSE image and confirming with the elemental mapping. The thermodynamic model prediction by Murdoch and Schuh [44] reports a weak segregation tendency of Ta in the W-Ta system. Therefore, the retardation in grain-boundary mobility, and hence finer grain sizes of SPS W-5wt.\%Ta, could be ascribed to a kinetic stabilization of the microstructure originating from a solute drag effect caused by the Ta.

\section{Conclusions}

In conclusion, the shrinkage/densification behavior and the microstructure evolution during non-isothermal and SPS of nanocrystalline W-5wt.\% Ta have been studied. An extensive Kirkendall-pore-induced expansion was observed during the non-isothermal sintering of the alloy. Almost 95\% relative density was achieved during SPS. The densification during SPS could be ascribed to dynamic pore-evolution-mediated enhanced point contacts which further 
help in localized heating. Interestingly, the average grain size for non-isothermally sintered $(1.64 \pm 0.9 \mu \mathrm{m})$ and the SPS W-5wt.\% Ta alloy $(1.73 \pm 1 \mu \mathrm{m})$ were found to be similar. Finally, it has been established that SPS could be a potential consolidation route to produce nano/ultrafine grain W-Ta alloys.

\section{Acknowledgements}

We are grateful to Dr. Jyoti Shankar Jha for his extended support in characterization of the samples.

\section{Disclosure statement}

No potential conflict of interest was reported by the author(s).

\section{Funding}

Ajeet K. Srivastav gratefully acknowledges the financial support from CSIR-India (via award no. 09/084(0519)2010-EMR-I).

\section{References}

[1] E. Lassner and W.-D. Schubert, Tungsten Properties, Chemistry, Technology of the Element, Alloys, and Chemical Compounds, Kluwer Academic/ Plenum Publishers, New York, 1999.

[2] A. Giannattasio, Z. Yao, E. Tarleton, and S.G. Roberts, Brittle-ductile transitions in polycrystalline tungsten, Philos. Mag. 90 (2010), pp. 3947-3959.

[3] R. Neu, R. Dux, A. Kallenbach, T. Pütterich, M. Balden, J. Fuchs, A. Herrmann, C. Maggi, M. O’Mullane, R. Pugno, I. Radivojevic, V. Rohde, A.C. Sips, W. Suttrop, A. Whiteford, and the A.U. Team, Tungsten: an option for divertor and main chamber plasma facing components in future fusion devices, Nucl. Fusion. 45 (2005), pp. 209 218.

[4] J.W. Davis, V.R. Barabash, A. Makhankov, L. Plöchl, and K.T. Slattery, Assessment of tungsten for use in the ITER plasma facing components, J. Nucl. Mater. 258-263 (1998), pp. 308-312.

[5] I. Ipatova, R.W. Harrison, P.T. Wady, S.M. Shubeita, D. Terentyev, S.E. Donnelly, and E. Jimenez-Melero, Structural defect accumulation in tungsten and tungsten- 
5wt.\% tantalum under incremental proton damage, J. Nucl. Mater. 501 (2018), pp. $329-335$.

[6] R.E. Nygren, R. Raffray, D. Whyte, M.A. Urickson, M. Baldwin, and L.L. Snead, Making tungsten work, J. Nucl. Mater. 417 (2011), pp. 451-456.

[7] I. Smid, M. Akiba, G. Vieider, and L. Plöchl, Development of tungsten armor and bonding to copper for plasma-interactive components, J. Nucl. Mater. 258-263 (1998), pp. 160-172.

[8] D. Rupp and S.M. Weygand, Anisotropic fracture behaviour and brittle-to-ductile transition of polycrystalline tungsten, Philos. Mag. 90 (2010), pp. 4055-4069.

[9] Y. Nemoto, A. Hasegawa, M. Satou, K. Abe, and Y. Hiraoka, Microstructural development and radiation hardening of neutron irradiated Mo-Re alloys, J. Nucl. Mater. 324 (2004), pp. 62-70.

[10] A. Giannattasio and S.G. Roberts, Strain-rate dependence of the brittle-to-ductile transition temperature in tungsten, Philos. Mag. 87 (2007), pp. 2589-2598.

[11] Y. Oh, N. Kwak, K. Lee, W.-S. Ko, and H.N. Han, Ductility enhancement of tungsten after plastic deformation, J. Alloys Compd. 787 (2019), pp. 801-814.

[12] H.-Y. Guo, M. Xia, L.-C. Chan, K. Wang, X.-X. Zhang, Q.-Z. Yan, M.-C. He, J. Lu, and C.-C. Ge, Nanostructured laminar tungsten alloy with improved ductility by surface mechanical attrition treatment, Sci. Rep. 7 (2017), pp. 1351.

[13] C. Linsmeier, M. Rieth, J. Aktaa, T. Chikada, A. Hoffmann, J. Hoffmann, A. Houben, H. Kurishita, X. Jin, M. Li, A. Litnovsky, S. Matsuo, A. von Müller, V. Nikolic, T. Palacios, R. Pippan, D. Qu, J. Reiser, J. Riesch, T. Shikama, R. Stieglitz, T. Weber, S. Wurster, J.-H. You, and Z. Zhou, Development of advanced high heat flux and plasmafacing materials, Nucl. Fusion. 57 (2017) 092007.

[14] B. Gludovatz, S. Wurster, T. Weingärtner, A. Hoffmann, and R. Pippan, Influence of impurities on the fracture behaviour of tungsten, Philos. Mag. 91 (2011), pp. 30063020.

[15] A. Calvo, C. García-Rosales, F. Koch, N. Ordás, I. Iturriza, H. Greuner, G. Pintsuk, and C. Sarbu, Manufacturing and testing of self-passivating tungsten alloys of different composition, Nucl. Mater. Energy. 9 (2016), pp. 422-429.

[16] O. El-Atwani, J.A. Hinks, G. Greaves, J.P. Allain, S.A. Maloy, Grain size threshold for enhanced irradiation resistance in nanocrystalline and ultrafine tungsten, Mater. Res. Lett. 5 (2017) 343-349. 
[17] V.M. Lunyov, A.S. Kuprin, V.D. Ovcharenko, V.A. Belous, A.N. Morozov, A. V. Ilchenko, G.N. Tolmachova, E.N. Reshetnyak, and R.L. Vasilenko, Structure and properties of W, Ta and W-Ta coatings deposited with the use of a gas-plasma source, Probl. At. Sci. Technol. 101 (2016), pp. 140-144.

[18] A. Xu, D.E.J. Armstrong, C. Beck, M.P. Moody, G.D.W. Smith, P.A.J. Bagot, and S.G. Roberts, Ion-irradiation induced clustering in W-Re-Ta, W-Re and W-Ta alloys: An atom probe tomography and nanoindentation study, Acta Mater. 124 (2017), pp. 71-78.

[19] W.H. Lenz and R.E. Riley, The Kirkendall effect in sintered refractory metal alloys, Tech. Rep. LA-4153-MS, Los Alamos Scientific Laboratory, New Maxico, 1969.

[20] A.K. Srivastav and B.S. Murty, Dilatometric analysis on shrinkage behavior during non-isothermal sintering of nanocrystalline tungsten mechanically alloyed with molybdenum, J. Alloys Compd. 536 (2012), pp. S41-S44.

[21] A.K. Srivastav, M. Sankaranarayana, and B.S. Murty, Initial-stage Sintering Kinetics of Nanocrystalline Tungsten, Metall. Mater. Trans. A. 42 (2011), pp. 3863-3866.

[22] N. Chawake, L.D. Pinto, A.K. Srivastav, K. Akkiraju, B.S. Murty, and R.S. Kottada, On Joule heating during spark plasma sintering of metal powders, Scr. Mater. 93 (2014), pp. 52-55.

[23] A.K. Srivastav, N. Chawake, D. Yadav, N.S. Karthiselva, and B.S. Murty, Localized pore evolution assisted densification during spark plasma sintering of nanocrystalline W-5wt.\%Mo alloy, Scr. Mater. 159 (2019), pp. 41-45.

[24] A.K. Srivastav, A.M. Panindre, and B.S. Murty, XRD Characterization of Microstructural Evolution During Mechanical Alloying of W-20 wt\%Mo, Trans. Indian Inst. Met. 66 (2013), pp. 409-414.

[25] A.K. Srivastav, J. Basu, S. Kashyap, N. Chawake, D. Yadav, and B.S. Murty, Crystallographic-shear-phase-driven W 18049 nanowires growth on nanocrystalline W surfaces, Scr. Mater. 115 (2016), pp. 28-32.

[26] A.K. Srivastav, N. Chawake, and B.S. Murty, Grain-size-dependent non-monotonic lattice parameter variation in nanocrystalline $W$ : The role of non-equilibrium grain boundary structure, Scr. Mater. 98 (2015), pp. 20-23.

[27] D. Balzar and H. Ledbetter, Voigt-function modeling in Fourier analysis of size-and strain-broadened X-ray diffraction peaks, J. Appl. Crystallogr. 26 (1993), pp. 97-103. 
[28] D. Balzar, Voigt-Function Model in Diffraction Line-Broadening Analysis, in Defect and Microstructure Analysis by Diffraction, R.L. Snyder, H.J. Bunge, J. Fiala, eds., Oxford University Press, New York, 1999, pp. 94-126.

[29] D. Balzar, BREADTH - a program for analyzing diffraction line broadening, J. Appl. Crystallogr. 28 (1995), pp. 244-245.

[30] T.H. de Keijser, J.I. Langford, E.J. Mittemeijer, and A.B.P. Vogels, Use of the Voigt function in a single-line method for the analysis of X-ray diffraction line broadening, $\mathrm{J}$. Appl. Crystallogr. 15 (1982), pp. 308-314.

[31] T. de Keijser, E.J. Mittemeijer, and H.C.F. Rozendaal, The determination of crystallite-size and lattice-strain parameters in conjunction with the profile-refinement method for the determination of crystal structures, J. Appl. Crystallogr. 16 (1983), pp. 309-316.

[32] D. Balzar, N. Audebrand, M.R. Daymond, A. Fitch, A. Hewat, J.I. Langford, A. Le Bail, D. Louër, O. Masson, C.N. McCowan, N.C. Popa, P.W. Stephens, and B.H. Toby, Size-strain line-broadening analysis of the ceria round-robin sample, J. Appl. Crystallogr. 37 (2004), pp. 911-924.

[33] B.E. Warren, X-Ray Diffraction, Dover Publications, New York, 1990.

[34] A. Dutta, N. Gayathri, S. Neogy, and P. Mukherjee, Microstructural characterisation of proton irradiated niobium using X-ray diffraction technique, Philos. Mag. 98 (2018), pp. 1031-1052.

[35] N.C. Halder and C.N.J. Wagner, Separation of particle size and lattice strain in integral breadth measurements, Acta Crystallogr. 20 (1966), pp. 312-313.

[36] D. Balzar and H. Ledbetter, Accurate modeling of size and strain broadening in the Rietveld refinement: The "Double-Voigt" approach, Adv. X-ray Anal. 38 (1995), pp. $397-404$.

[37] T. Adler and C.R. Houska, Simplifications in the x-ray line-shape analysis, J. Appl. Phys. 50 (1979), pp. 3282-3287.

[38] T. Kamiyama, T. Shinohara, S. Tomiyoshi, Y. Minonishi, H. Yamamoto, H. Asano, and N. Watanabe, Effect of deformation on Pd 2 MnSn Heusler alloy studied with transmission electron microscopy, profile analysis of neutron powder diffraction pattern, and magnetization measurement, J. Appl. Phys. 68 (1990), pp. 4741-4750.

[39] R.L. Rothman and J.B. Cohen, X-Ray study of faulting in BCC metals and alloys, J. Appl. Phys. 42 (1971), pp. 971-979. 
[40] J.B. Nelson and D.P. Riley, An experimental investigation of extrapolation methods in the derivation of accurate unit-cell dimensions of crystals, Proc. Phys. Soc. 57 (1945), pp. $160-177$.

[41] A.D. Romig and M.J. Cieslak, Interdiffusion in the Ta-W system, J. Appl. Phys. 58 (1985), pp. 3425-3429.

[42] Y. Liu, L. Zhang, Y. Du, J. Wang, and D. Liang, Study of atomic mobilities and diffusion characteristics in bcc Ti-Ta and Ta-W alloys, Calphad. 34 (2010), pp. 310 316.

[43] R.T. Ott, X.Y. Yang, D.E. Guyer, S. Chauhan, and D.J. Sordelet, Synthesis of highstrength W-Ta ultrafine-grain composites, J. Mater. Res. 23 (2008), pp. 133-139.

[44] H.A. Murdoch and C.A. Schuh, Estimation of grain boundary segregation enthalpy and its role in stable nanocrystalline alloy design, J. Mater. Res. 28 (2013), pp. 2154 2163. 